\title{
Treatability Performance of Kempas, Eucalyptus and Pine Sleepers with Coal-Tar Creosote
}

\author{
E.M.B.M. Karunathilake ${ }^{1 *}$, H.S. Amarasekera ${ }^{1}$, M.C. Dewendra ${ }^{2}$ \\ ${ }^{I}$ Department of Forestry and Environmental Science, University of Sri Jayewardenepura, Sri Lanka \\ ${ }^{2}$ State Timber Corporation, Battaramulla, Sri Lanka \\ *pscimat26@gmail.com
}

\begin{abstract}
Treating wood with coal tar creosote increases its service life by preventing biological deterioration. For the present study, creosote, major oil borne preservative was used to treat railway sleepers. In Sri Lanka, State Timber Corporation import Kempas railway sleepers from Malaysia and re-export to Singapore after treating them with coal tar creosote in creosote: furnace oil ratios of 90:10 or 80:20. Eucalyptus sleepers are also treated with coal tar creosote in creosote: furnace oil ratio of 50: 50 according to the BS 144 Standards.

Furnace oil acts as a carrier of creosote and increase the penetration and retention of preservatives in wood. The effect of creosote:furnace oil ratios of 90:10, 80:20, 70:30 and 50:50 on penetration and retention of Kempas, Eucalyptus and Pinus sleepers were measured with and without incising using $5 \times 5 \times 45 \mathrm{~cm}$ sample poles. Retention is the quantity of creosote remaining in the poles after the treatment which should not be less than $115 \mathrm{~kg} / \mathrm{m}^{3}$ according to the BS144 standards. Average retention of creosote furnace oil mixture of 50:50 in incised Kempas poles was found to be $157.43 \mathrm{~kg} / \mathrm{m}^{3}$. Pine had the retention value of $320.85 \mathrm{~kg} / \mathrm{m}^{3}$ even without incising while Eucalyptus showed the retention value of 48.11 $\mathrm{kg} / \mathrm{m}^{3}$ without incising which is below the standard value. The moisture content was below $25 \%$. Penetration refers to how deeply the preservative enters the wood which should not be less than $2.2 \mathrm{~cm}$, according to the BSEN 351-1:1995 standard. Incised Kempas showed 2.067 $\mathrm{cm}$ penetration while Eucalyptus and Pine showed $0.679 \mathrm{~cm}$ and $2.200 \mathrm{~cm}$ without incising. Pine (soft wood species) showed the higher penetration and retention values compared with Eucalyptus. Kempas (hardwood species) had higher penetration and retention values than Eucalyptus after incision.
\end{abstract}

Keywords: Creosote, Retention, Penetration, Pressure treatment, Kempas, Eucalyptus, Pine 